\title{
The Experimental Study on FGD-Gypsum Improving Coastal Saline-Soil
}

\author{
Sanyan DU \\ Institute of Ecological Technology and Engineering \\ Shanghai Institute of Technology \\ Shanghai, 201418, China \\ e-mail: 562578846@qq.com
}

\author{
Meifang HOU \\ Institute of Ecological Technology and Engineering \\ Shanghai Institute of Technology \\ Shanghai, 201418, China \\ e-mail: mfhou@sit.edu.cn
}

\author{
Xiaohua CHEN \\ Shanghai Academy of Environmental Sciences \\ Shanghai, 200233, China \\ e-mail: shoutfar@aliyun.com
}

\begin{abstract}
Two kinds of flue gas desulfurization gypsum (FGDgypsum) A\# and B\# were chosen to improve coastal saline-soil at the different ratios of quality $(0 \%, 0.5 \%, 1 \%, 2.5 \%, 5 \%)$ respectively in soil column leaching experiment. A came from a steelworks whose technology was wet gas gush churn tower sintering flue gas desulfurization and $B$ came from a coal-fired power plant whose technology was conventional spray wet limestone-gypsum flue gas desulfurization, A gypsum contained more impurities than $B$. The results showed that, compared with the control, applying A could increase soil saturated hydraulic conductivity and leaching sodium quality by 5 6 times, 11.0\% 22.2\%, and decrease soil $\mathrm{pH}$, exchangeable sodium percentage (ESP) by 0.41 0.11, $25.1 \% \sim 76.7 \%$, respectively. The improvement effect of $B$ was superior than that of $\mathrm{A}$ due to higher $\mathrm{Ca}^{2+}$ dissolution efficiency and lower chloride ion content of $B$. Compared with A, B could increase soil saturated hydraulic conductivity and leaching sodium quality by $57.5 \% \sim 89.1 \%, 51.3 \% \sim 74.0 \%$, and decrease soil pH, ESP by $0.10 \sim 0.36,66.7 \% \sim 83.6 \%$, respectively. When two kinds of FGD-gypsum improving coastal saline-soil, the change rules of soil's physical and chemical properties were that, with increasing ratios of FGD-gypsum, soil saturated hydraulic conductivity increased before leveling off, leaching sodium quality gradually increased, soil pH declined before leveling off, ESP gradually reduced. And soil leaching sodium quality had relationship with the improvement of soil hydraulic conductivity and the substitution reaction of sodium and calcium. The application of FGD-gypsum to improve saline-soil, this kind of FGD-gypsum which has low chloride ion content, high calcium ion dissolution efficiency is recommended.
\end{abstract}

Keywords-flue gas desulfurization gypsum; coastal saline soil; soil improvement; $\boldsymbol{E S P}$

\section{INTRODUCTION}

In China, coastal saline-soil accounts for about $17.2 \%$ of the total soil area of the coastal zone, which mainly distributes in eastern coastal areas of the North China plain, such as Liaodong Bay, Bohai Bay, Laizhou Bay and the coastal areas of Jiangsu and Zhejiang, is an important soil resource. Soil salinization severely restricts the land use of
Binhai area. Binhai area has a large coastal saline-soil due to low topography, high underground water level, water erosion, soil evaporation, reclamation projects, deforestation, and so on [1]. The physical and Chemical Properties of coastal saline-soil are very bad for high salt content, high underground water level, low natural desalting rate, serious salinization degree [2]-[3]. Improving coastal saline soil is important in that it could relieve commerce-favored ideology, improve the ecological environment and benefit resource exploitation and utilization, etc.

In recent years, flue gas desulfurization gypsum (FGDgypsum) as a soil amendment is popular for its low cost, large output, quick repair efficiency [4]-[5]. Based on the researches home and abroad, FGD-gypsum could increase soil porosity, accelerate soil desalination, reduce the exchangeable sodium percentage (ESP) through flocculating soil clay particles and exchanging exchangeable sodium ions, could provide nutrients for plants (such as $\mathrm{Ca}, \mathrm{S}, \mathrm{Si}, \mathrm{Fe}$ ), could reduce the transport of nutrients, sediment, pesticides and other contaminants to surface waters [6]-[9]. FGDgypsum has already been applied in agriculture in America, and it is supported by the EPA and the USDA. In 2008, the EPA issued " Agricultural Uses for Flue Gas Desulfurization (FGD) Gypsum ". In 2015, the USDA formally promulgated FGD-gypsum as a new optimal soil amendment of state practice. Therefore, FGD-gypsum usage will substantial increase [9]-[10].

In China, A large amount of FGD-gypsum are producted from coal-fired power plants, steelworks, and other industries every year. Coal-fired power plant and steelworks are different industries, their flue gas composition, desulfurization process, desulphurizers are quite different. Steelworks'flue gas desulfurization is more difficult and more complicated than that of coal-fired power plant, and its FGD-gypsum produced is also different from that of coalfired power plant [11]. FGD-gypsum's sources are different, whether they can also generate different improvement effects for saline-soil. In this speculation, this paper chose two different types of FGD-gypsum from a steelworks and a coal-fired power plant respectively to improve coastal saline- 
soil. In this study, soil saturated hydraulic conductivity, leaching sodium quality, $\mathrm{pH}$, exchangeable sodium percentage were detected to compare the improvement effects of two kinds of FGD-gypsum in soil column leaching experiment for finding the kind of FGD-gypsum which had better improvement effect for saline-soil.

\section{OBJECTS AND Methods}

\section{A. Soil Samples and FGD Gypsum}

Soil samples were taken from Chongming Island (30³1'25" N 121 57'20" E) in Shanghai, China, which is located in the Yangtze River. The region has a typical subtropical monsoon climate, the annual average temperature is $15.3^{\circ} \mathrm{C}$, the hottest months are July and August (monthly average temperature $26.8-26.9^{\circ} \mathrm{C}$ ), and the annual average evaporation capacity $(1346 \mathrm{~mm})$ is higher than the annual average precipitation $(1078 \mathrm{~mm})$ [12]-[14]. The soil samples were collected in the tillage layer $(0-20 \mathrm{~cm})$, then air-dried, disaggregated, sieved $(2 \mathrm{~mm})$, and mixed well for soil column leaching experiment. The physicochemical

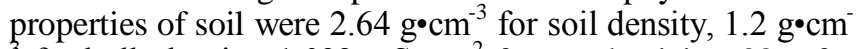
3 for bulk density, $1.092 \mathrm{mS} \cdot \mathrm{cm}^{-2}$ for conductivity, $38 \%$ for moisture content, $1.29 \times 10^{3} \mathrm{mg} \mathrm{kg}^{-1}$ for soil total salt, 9.07 for $\mathrm{pH}, 30.61 \%$ for ESP, which belonged to typical severe saline-soil, and the soil main soluble salt was sodic salt [10].

Two kinds of FGD-gypsum A and B were chosen from a steelworks and a coal-fired power plant. A which belonged to sintering FGD-gypsum came from a steelworks whose technology was still in the developing stage of wet gas gush churn tower sintering flue gas desulfurization and desulphurizer was water-washing limestone mud cake of steelworks, had many impurities. B came from a coal-fired power plant whose technology was a most mature and stable operation of conventional spray wet limestone-gypsum flue gas desulfurization and desulphurizer was limestone slurry maded from industrial water, had less impurities than $\mathrm{A}$. The FGD-gypsum samples were treated through being air-dried in a cool dark place, disaggregated, and sieved (2 mm). Two kinds of FGD-gypsum's basic physical and chemical properties are shown in Table I. Table I shows that, the mainly differences between FGD-gypsum A\# and B\# are the content of impurity-chlorine ion (the content of impuritychlorine ion of $\mathrm{A \#}$ is 5.758 times that of $\mathrm{B \#}$ ) and dissolution rate of calcium ions (calcium ions dissolution rate of $A \#$ is 1.185 times that of $\mathrm{B} \#$ ). In the aspect of particle size, A and $\mathrm{B}$ had no significant difference, and their particles ranged mainly from $30 \mathrm{~mm}$ to $50 \mathrm{~mm}$.

TABLE I. PHysicAl AND CHEMICAL PROPERTIES OF FGD-GYPSUM

\begin{tabular}{lll}
\hline $\begin{array}{l}\text { Physical and chemical properties of } \\
\text { FGD-gypsum }\end{array}$ & A\# & B\# \\
\hline $\mathrm{pH}$ & 7.98 & 7.94 \\
$\mathrm{Color}$ & Palm red & Yellow fraction \\
$\mathrm{Cl}^{-} / \mathrm{mg}^{\prime} \mathrm{kg}^{-1}$ & 3800 & 660 \\
$\mathrm{Saturated} \mathrm{liquid} \mathrm{Ca}^{2+} / \mathrm{mg} \cdot \mathrm{L}^{-1}$ & 337.1 & 399.45 \\
$\mathrm{CaSO}_{4} \cdot 2 \mathrm{H}_{2} \mathrm{O} / \%$ & 94 & 93 \\
\hline
\end{tabular}

\section{B. Soil Column Leaching Experiment}

Soil column leaching device is shown in Figure 1. Soil column leaching experiment was conducted with nine treatments, which were the natural soil, A\# gypsum mixed with the natural soil at mass concentrations of $0.5 \%, 1 \%$, $2.5 \%, 0.5 \%, \mathrm{~B} \#$ gypsum mixed with the natural soil at mass concentrations of $0.5 \%, 1 \%, 2.5 \%, 0.5 \%$, each treatment was repeated thrice. After soil columns filled, soil columns were leached by deionized water, and deionized water leaching volume was designed to $1100 \mathrm{~mL}$ for simulating the average annual rainfall of Shanghai.

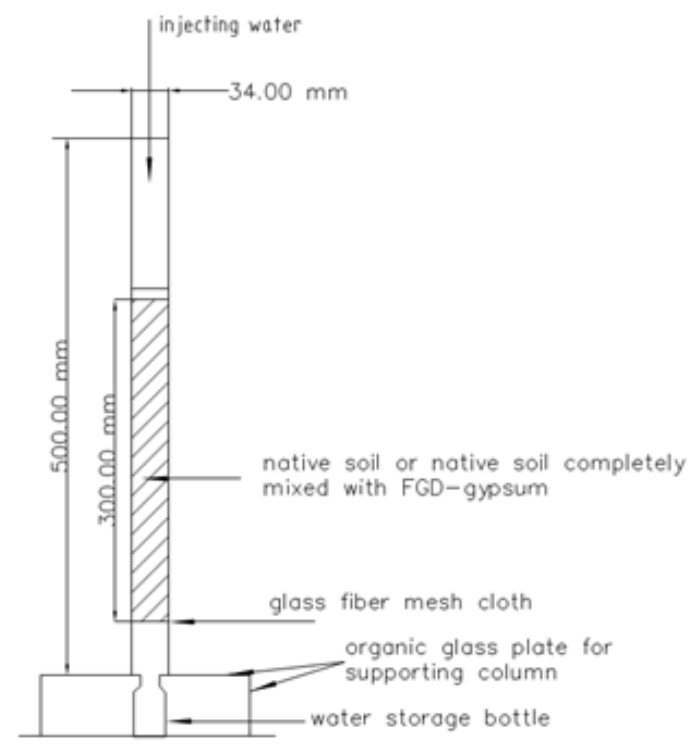

Figure 1. Soil column leaching experiment equipment

\section{Analysis and Method}

Selected soil characteristics were determined in accordance with the NY/T 1121-2006 soil testing standards [15]. The sodium ion content in the leachate samples was determined by a flame furnace atomic absorption spectrophotometer. Soil $\mathrm{pH}$ was determined on a 1:5 (soil:water, W/W) mixture using a glass electrode. The exchangeable, sodium ion $\left(\mathrm{Na}^{+}\right)$, cations, which were extracted using $1 \mathrm{~mol} / \mathrm{L} \mathrm{NH}_{4} \mathrm{OAc}$, whose concentrations were measured using an flamephotometer. The ESP was calculated by the percentage of exchangeable sodium in soil exchangeable cations where soil exchangeable sodium and exchangeable cations were expressed in $\mathrm{cmol} / \mathrm{kg}$.

The soil saturated hydraulic conductivity was determined through the collected volume of leachate from soil column per hour [16].

Selected FGD-gypsum characteristics were determined in accordance with the GB/T 5484-2012 methods for chemical analysis of gypsum.

\section{Data Analysis}

ORIGIN 9.0 and SPSS 17.0 were used to deal with the experimental data. Unless special instructions, the chart data are the average values of repeated treatment. 


\section{RESUlTS AND DiSCUSSION}

\section{A. Soil Saturated Hydraulic Conductivity}

When examining Figure 2, it is apparent that two kinds of FGD-gypsum-A\#, B\#- accelerate soil saturated hydraulic conductivity which is close to the maximum when the quality ratio of FGD-gypsum is more than $1 \%$. Compared with the control, applying A\# gypsum could increase soil saturated hydraulic conductivity by $5 \sim 6$ times, applying B\# gypsum could increase soil saturated hydraulic conductivity by $9 \sim 12.5$ times. Applying B\# gypsum could increase soil saturated hydraulic conductivity by $57.5 \% \sim 89.1 \%$ compared with A. B\# was superior to A\# at accelerating soil saturated hydraulic conductivity.

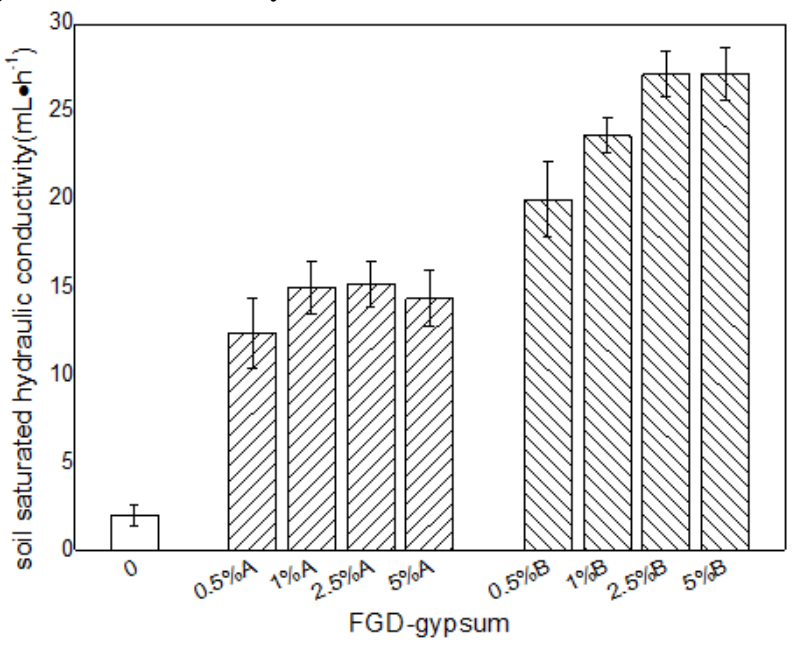

Figure 2. Soil saturated hydraulic conductivity under different rates of FGD-gypsum application

The result shows that FGD-gypsum can play an important role in the improvement of soil saturated hydraulic conductivity. Soil saturated hydraulic conductivity increases before leveling off with increasing ratios of FGD-gypsum, which is similar to the study of Cheng et al. [17]. FGDgypsum could accelerate soil hydraulic conductivity is due to that FGD-gypsum increases calcium ions in soil and positively charged calcium ions could reduce dispersion of soil particles by promoting the aggregation of negatively charged clay particles, which improves the stability of soil structure and prevents soil crusting. Better soil particle aggregation and less crusting allow for greater soil saturated hydraulic conductivity [9].

\section{B. Soil Leaching Sodium Quality}

The main salt of the soil used in this study was sodium salt and sodium ion is the main reason that causes the bad physical and chemical properties of saline-soil [18]. Therefore, only soil leaching sodium is involved in leaching salt in this paper.

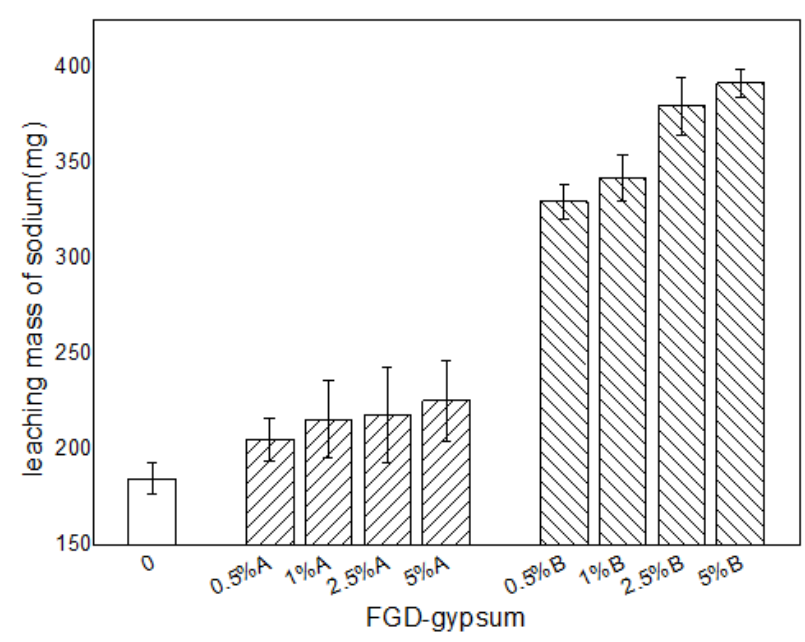

Figure 3. Leaching sodium quality under different rates of FGD-gypsum application

When examining Figure 3, it is apparent that two kinds of FGD-gypsum-A\#, B\#- accelerate soil to leach sodium and leaching sodium quality gradually increases with increasing ratios of FGD-gypsum. Applying A\# gypsum could increase leaching sodium quality by $11.0 \% \sim 22.2 \%$ and applying B\# gypsum could increase leaching sodium quality by $78.4 \% \sim 111.7 \%$, compared with the control. Applying B\# gypsum could increase leaching sodium quality by $51.3 \%$ 74.0\% compared with A. B\# was superior to A\# at accelerating soil to leach sodium.

The result shows that FGD-gypsum can play an important role in accelerating soil to leach sodium, which is similar to the study of $\mathrm{Yu}$ et al [19]. FGD-gypsum can accelerate soil to leach sodium is due to that the improvement of soil saturated hydraulic conductivity and the substitution reaction of sodium and calcium. Within a certain range, the faster soil hydraulic conductivity, the more leaching sodium quality of soil is. leaching sodium of soil derives from water-extractable sodium and exchangeable sodium replaced by calcium ion from FGD-gypsum [17], leaching sodium of soil is related to soil hydraulic conductivity and the ratio of FGD-gypsum. In Figure 3, leaching sodium of soil slightly increases when the soil saturated hydraulic conductivity is tended to equilibrium, which indicates that soil hydraulic conductivity is dominant for accelerating sodium leaching in this study.

\section{Soil pH}

When examining Figure 4, it is apparent that, $\mathrm{B} \#$ is superior to $\mathrm{A \#}$ at reducing soil $\mathrm{pH}$, both $\mathrm{A \#}$ and $\mathrm{B \#}$ could reduce soil $\mathrm{pH}$, soil $\mathrm{pH}$ declines before leveling off with increasing ratios of FGD-gypsum. Applying A\# gypsum could reduce soil $\mathrm{pH}$ by $0.41 \sim 1.11$ units, applying $\mathrm{B \#}$ gypsum could reduce soil $\mathrm{pH}$ by $0.77 \sim 1.21$ units, compared with the control. 


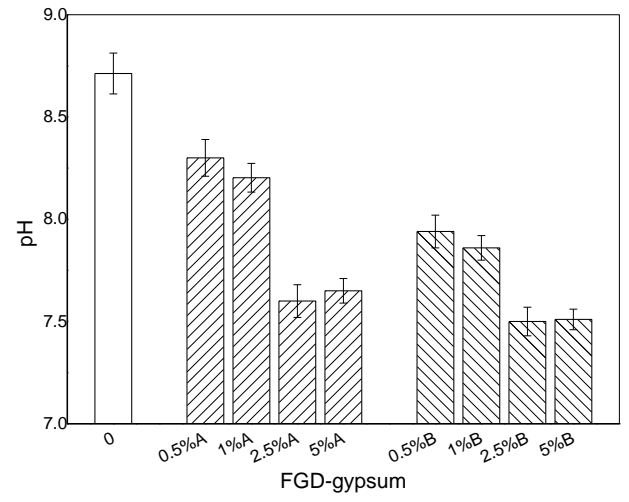

Figure 4. Soil pH under different rates of FGD-gypsum application in Soil column experiment

Studies of Sakai et al.[20] and LI et al.[21] also have shown that FGD-gypsum could reduce soil $\mathrm{pH}$ and reducing extent of soil $\mathrm{pH}$ is not proportional to the ratio of FGDgypsum. Soil $\mathrm{pH}$ is controlled by exchangeable sodium and water-soluble $\mathrm{CO}_{3}{ }^{2-}+\mathrm{HCO}_{3}{ }^{-}$. Soil $\mathrm{pH}$ reduced is due to that calcium ion from FGD-gypsum reacts with $\mathrm{CO}_{3}{ }^{2-}+\mathrm{HCO}_{3}{ }^{-}$to generate $\mathrm{CaCO}_{3}$ deposition and replaces exchangeable sodium which is leached out.

\section{Soil Alkalinity}

When examining Figure 5, it is apparent that the cation exchange capacity (CEC) of A\# gypsum treatments, B\# gypsum treatments and the control have no significant difference $(\mathrm{P}<0.05)$, which means FGD-gypsum will not reduce the water retain and fertilizer of soil. And the change rule of ESP is similar to that of exchangeable sodium, which gradually reduces with increasing ratios of FGD-gypsum. Applying A\# gypsum could reduce the soil ESP by $25.1 \% \sim 76.7 \%$ compared with the control, and the biggest drop of soil ESP was from the ratio of $0.5 \%$ to $1 \%$. Applying B\# gypsum could reduce the soil ESP by $87.8 \%$ 93.5\% compared with the control, and the ratio of $0.5 \%$ had reached a very good improvement effect for the ESP. B\# was superior to A\# at reducing the soil exchangeable sodium and ESP.

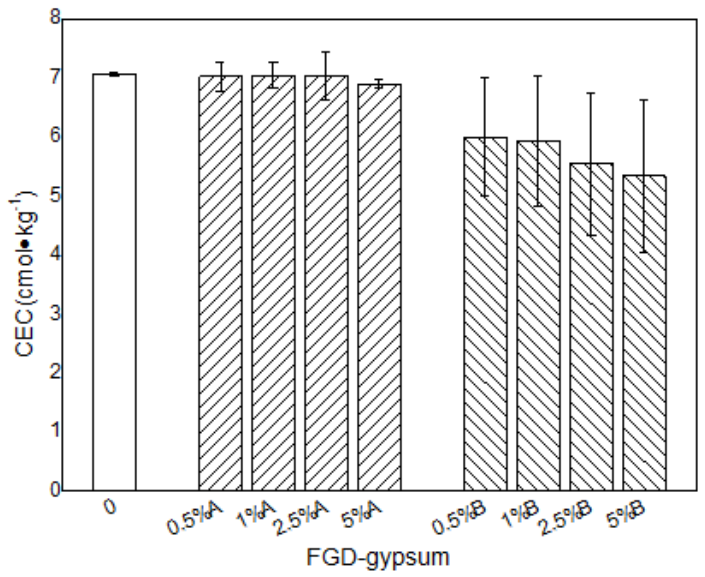

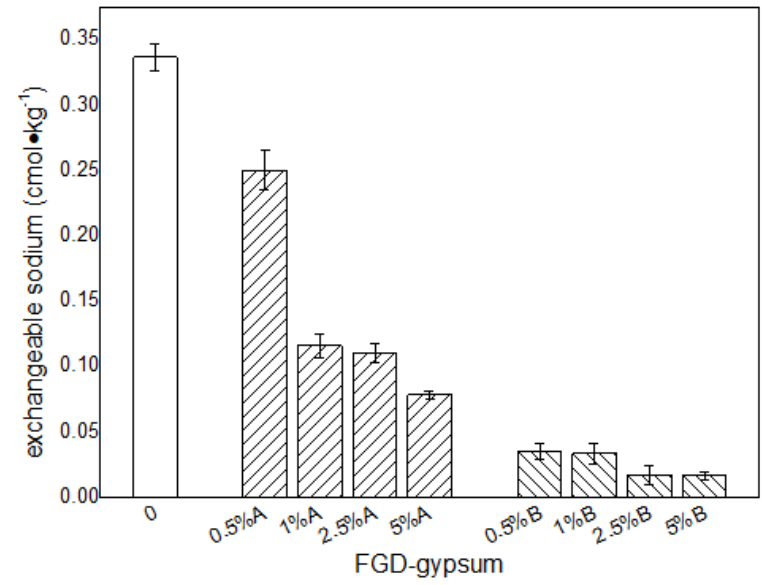

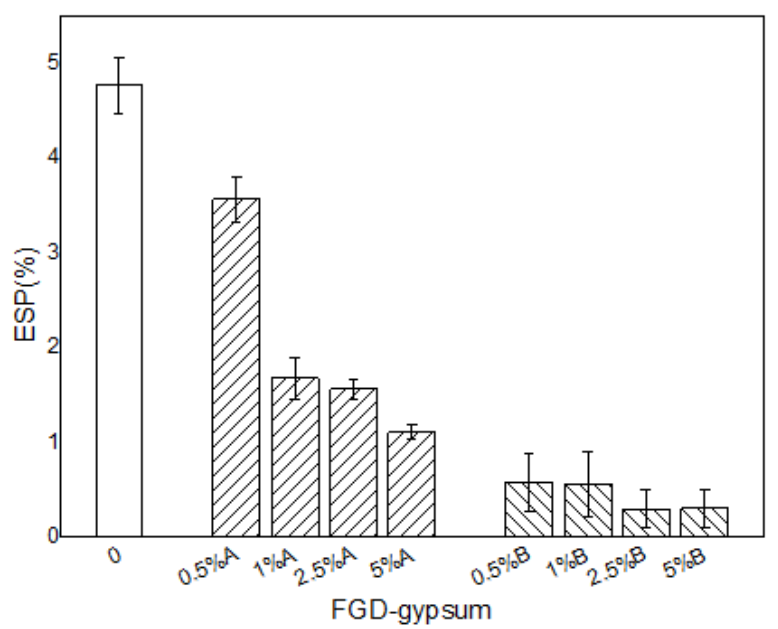

Figure 5. Soil CEC, exchangeable sodium, ESP under different rates of FGD-gypsum application in Soil column experiment

Study of Mao et al. [10] has shown that FGD-gypsum cannot reduce soil CEC which represents soil's water retain and fertilizer. The key to the improvement of saline-soil is the reduction of soil ESP. FGD-gypsum reducing soil ESP is due to that, calcium ion's flocculation ability for soil clay is superior to that of sodium ion [6], calcium ion from FGDgypsum could replace exchangeable sodium in soil colloids, then soil ESP is reduced [22].

According to the above results of Part III, A\# was similar to B\# for the change rules of soil's key physical and chemical properties when improving the coastal saline-soil, but B\# gypsum was superior to A\# for improvement effect.

Throughout FGD-gypsum improving saline-soil, calcium ion is the key to improve soil's physical and chemical properties, which is consistent with the study of Li et al. [23]. The calcium ion dissolution efficiency of B\# gypsum was superior to that of A\# so that $\mathrm{B} \#$ was superior $\mathrm{A \#}$ for the improvement effect of soil. In addition, the impurity of FGDgypsum-chloride ion has an influence on the improvement of saline-soil. According to the study of Liu et al. [24], calcium chloride and calcium sulfate have common-ion effect, chloride ion which can combine with calcium ion could hinder the dissolution of calcium sulfate from FGD- 
gypsum. Meanwhile, chloride ion whose volume is very large could block up FGD-gypsum-soil system's desalination reaction space and leaching salt space [19]. Dissolution efficiency of calcium ion and content of chlorine ion of FGD-gypsum could affect the improvement effect of salinesoil. B\# gypsum superior to A\# for improvement effect of coastal saline-soil is due to higher calcium ion dissolution efficiency and lower chloride ion content of B\# gypsum.

\section{CONCLUSIONS}

In soil column leaching experiment, both $\mathrm{A \#}$ gypsum from a steelworks whose technology was wet gas gush churn tower sintering flue gas desulfurization and B\# gypsum from a coal-fired power plant whose technology was conventional spray wet limestone-gypsum flue gas desulfurization can improve the physical and chemical properties of coastal saline-soil. When two kinds of FGD-gypsum improved the coastal saline-soil, the change rules of soil's physical and chemical properties were that, soil saturated hydraulic conductivity increased before leveling off, leaching sodium quality gradually increased, soil $\mathrm{pH}$ declined before leveling off, ESP gradually reduced with increasing ratios of FGDgypsum, and soil leaching sodium quality had relationship with the improvement of soil hydraulic conductivity and substitution reaction of sodium and calcium.

B\# gypsum was superior to A\# for the improvement effect of the coastal saline-soil due to higher calcium ion dissolution efficiency and lower chloride ion content of B\# gypsum. The application of FGD-gypsum to improve salinesoil, this kind of FGD-gypsum which has low chloride ion content, high calcium ion dissolution efficiency is recommended.

\section{REFERENCES}

[1] Mei, Dexin, Deshun Zhang and Zhen Wang. 2013. "The Status and Trends of Ecological Restoration of Saline-alkali Land in Coastal Region." Chinese Agricultural Science Bulletin, 24(2), 10-14.

[2] P. Rengasamy. 2006. "World salinization with emphasis on Australia. Journal of experimental botany." 57(5), 1017-1023.

[3] Huang, Mingyong, Minsheng Zhang and Xing Zhang. 2009. "Research on Urban Landscape Technologies in Coastal Salt-alkali Region-A Review of Salt-alkali Coast Landscaping in TEDA." Chinese Landscape Architecture, 25(9), 7-10.

[4] Wang, Shunjuan, Qun Chen and Yan Li. 2016. "Research on salinealkali soil amelioration with FGD gypsum." Resources, Conservation and Recycling.

[5] Yang, Zhen, Baoshan Wang. 2014. "Progress in Techniques of Improvement and Utilization of Saline-Alkali Land in China and Its Future Trend." Open Journal of Soills\&lswater Conservation, 2014, 02(01):1-11

[6] Walworth, J. 2012. "Using Gypsum and Other Calcium Amendments in Southwestern Soils." Walworth James.

[7] W. A. Dick. 2006. "FGD as a Soil Amendment for Mine Reclamation."
[8] D. B. Watts, W. A. Dick. 2014. "Sustainable Uses of FGD Gypsum in Agricultural Systems: Introduction." Journal of environmental quality, 43(1), 246-252.

[9] US EPA, 2008. Agricultural uses for flue gas desufurization (FGD) gypsum (EPA530-F-08-009).

[10] Mao, Yumei. 2016. "Flue gas desulfurization gypsum improving saline-sodic soil in tidal flats." PhD diss. China, Shanghai: East China Normal University.

[11] Wang, Ruyi, Xiaolin Shen and Lei Shi. 2008. "Characteristics of Gypsum Produced in the Sintering Flue Gas Desulphurization on Process at Bao steel." Bao-Steel Technology, (3), 29-32.

[12] Zhao, Jinxia, Hao Liu and Liquan Zhang. 2008. "Spatial Patterns for the Distribution of Winter Waterbirds in the Aquaculture Ponds of Chongming Dongtan, Shanghai." Zoological Research, 29(2), 212218.

[13] Wang, Qing. 2006. "The emission of greenhouse gases from the Chongming Dongtan wetland ecosystem and its mechanism." Master's thesis. China, Shanghai: East China Normal University.

[14] Mao, Yumei, Xiaoping Liu and W. A. Dick. 2016. "Remediation of saline-sodic soil with flue gas desulfurization gypsum in a reclaimed tidal flat of southeast China." Journal of environmental sciences, 45, 224-232.

[15] MoA (Ministry of Agriculture of the People's Republic of China). (2006). Agricultural Standard of People's Republic of China: Soil Testing, NY/T 1121-2006.

[16] Hao, Zhenchun, Guiyang An and Jiahu Wang. 2012. "Laboratory measurement of soil saturated hydraulic conductivity in source region of Yellow River." Journal of Hohai University(Natural Sciences), 40(1), 9-12

[17] Cheng, Jingrun, Xiaohua Chen and Zhenhong Liu. 2014. "The experimental study on the process and effect to the FGD-gypsum as an improvement in coastal saline-alkali soil." China Environmental Science, 34(6): 1505-1513.

[18] Cheng, Wenjuan, Jie Pan and Hui Xiao. 2011. "Effect of combined frozen saHne water irrigation and soiI amendment on coastal saline Iand reclamation." Chinese JournaI of Eco-AgricuIture, 19(4), 778782.

[19] Yu, Haoliang. 2015. "Mechanism and quantitative characterization of changes of sodic soil structure under the effect of reclamation using Flue Gas Desulphurized Gypsum." PhD diss. China Agricultural University.

[20] Y. Sakai, S. Matsumoto and M. Sadakata. 2010. "Alkali Soil Reclamation with Flue Gas Desulfurization Gypsum in China and Assessment of Metal Content in Corn Grains." Soil and Sediment Contamination: An International Journal, 13(1), 65-80.

[21] Li, Yubo, Qingtao Xu. 2013. "Study on the Effect of the Use of FGD Gypsum into the Alkalization Soil to Improve Soil Property." Applied Mechanics and Materials, 448-453, 482-487.

[22] Chen, Qun, Shunjuan Wang and Yan Li. 2015. "Influence of Flue Gas Desulfurization Gypsum Amendments on Heavy Metal Distribution in Reclaimed Sodic Soils." Environmental engineering science, 32(6), 470-478.

[23] Li, huanzhen, Yupei Xu and Weiqi Yang. 1999. "Study on Effect of Using Sulfur-Remaral Gypsum as an Amendment to the Heavy Soda Saline-Alkali Soil." Chinese Journal of Ecology, (1), 25-29.

[24] Liu, Jie, jiannjun Yuan. 2010. "Calcium sulfate scaling and its advances in application of control techniques." Tianjin Chemical Industry, 24(2), 10-14. 